\title{
أثر تطبيق قانون النقد و القرض 03 - 11 على تنافسية وأداء في الجهاز المصرفي الجزائري 2004 - 2008
}

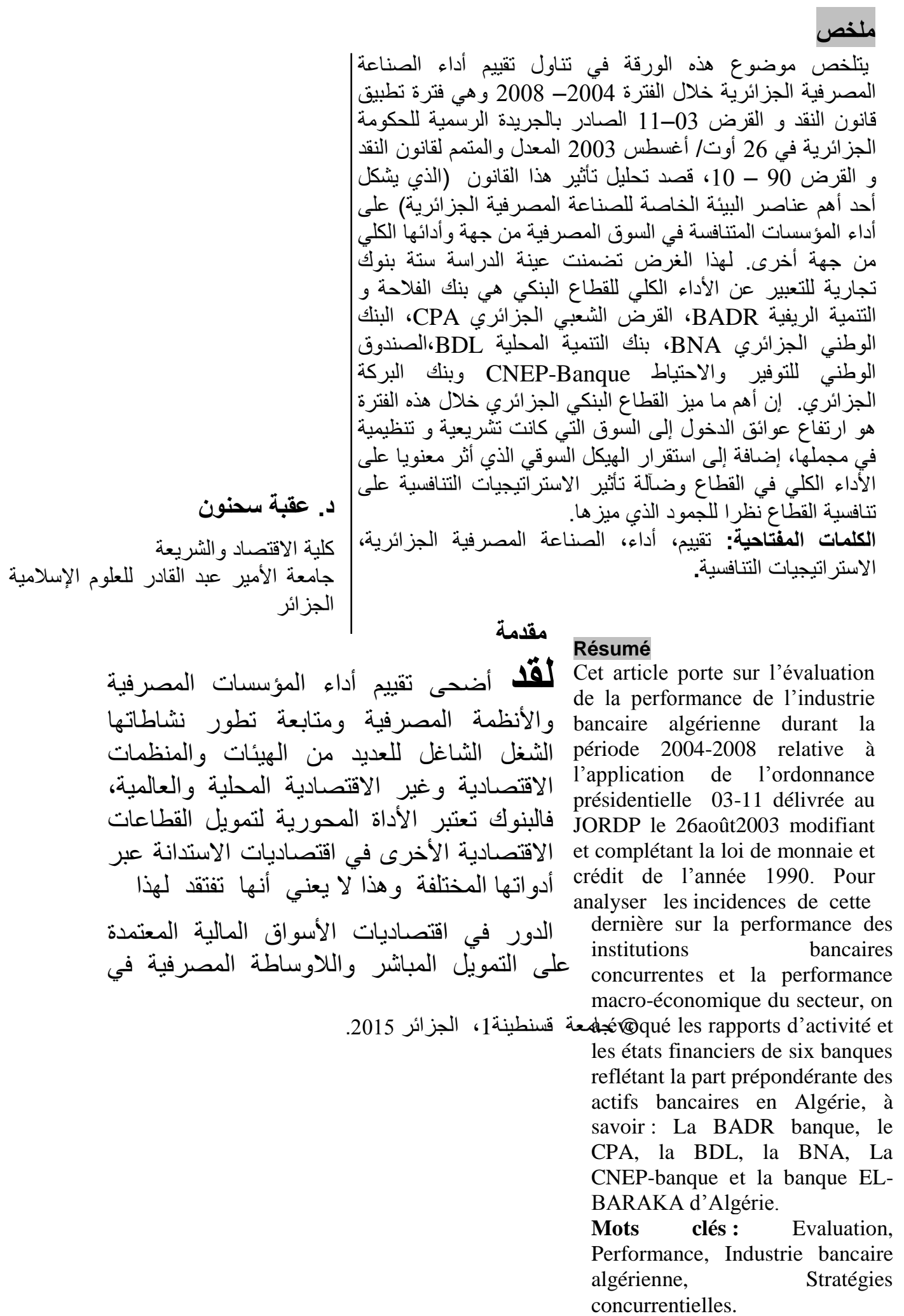


حين يكمن اختلاف دور ها في قيامها

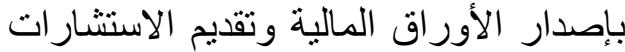

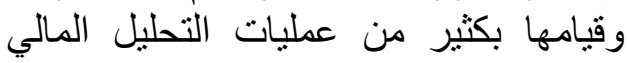
وتقييم المشاريع الاستثمارية.

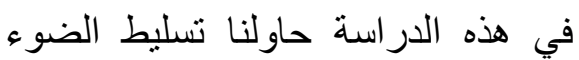
على تقييم أداء الجهاز المصرفي الجزائري

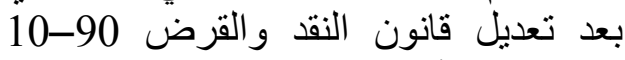

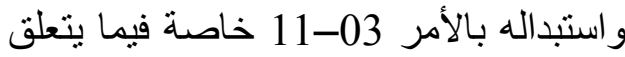
بوانب تشديد الرقابة واستحداث الهيئات

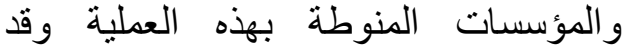
امتدت هذه الدراسة منذ دخول الأمر 03-

حيز التنفيذ إلى غاية سنة 2008، وهو ما يشكل (الجانب التشريعي للجهاز المصرفي) أهم عناصر البيئة الداخلية للصناعة المصرفية الجز ائرية.

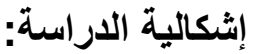

تتلخص إثنكالية هذه الدراسة في التساؤل الرئيسي التالي: كيف كان أداء الجهاز المصرفي الجزائري وتنافسيته بعد تعديل قانون النقد و القرض 90-10 و استبداله بالأمر 03 - 11 ؟

تندرج ضمن هذه الإشكالية بعض التساؤلات الفرعية نوجز ها في الآتي:

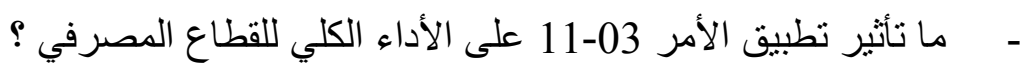
- ما علاقة هيكل السوق المصرفية بالربحية في القطاع المصرفي في الفترة الفئ

- - كيف كان أداء البنوك المتنافسة في فترة تطبيق الأمر 03 - 11 ؟

لوضع البحث في قالبه المنهجي اقترحنا الفرضيات التالية:

- تميز أداء القطاع المصرفي خلال الفترة 2004-2008 بمواكبة السياسة الاقتصادية العامة للدولة الجز ائرية.

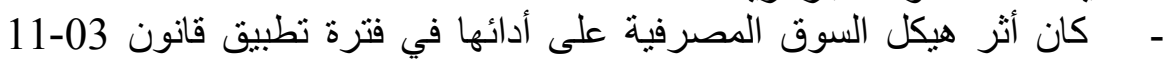

محدودا نظر اللإطار الجديد الذي تمارس فيه المهن المصرفية.

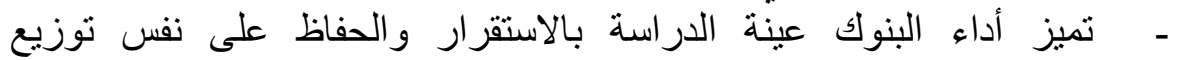

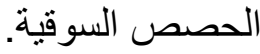


تكمن أهمية دراسة نأثير التغير في الإطار التشريعي للبيئة البنكية الجزائرية على التى

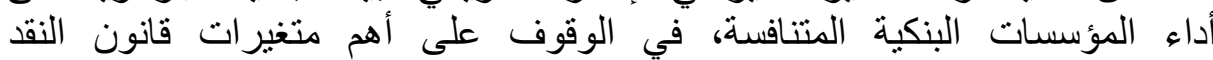

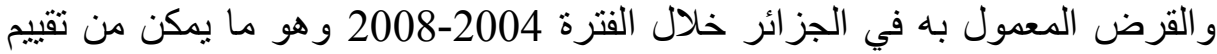
الأداء الكلي للقطاع المصرفي، وأهم آثاره على تنافسية المؤسسات المالية والئنية البنكية

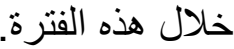

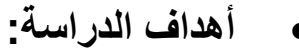

تهدف دراسة أثر تطبيق قانون النقد والقرض 03-11 على أداء القطاع البنكي في

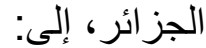

- - الاطلاع على أسباب تعديل قانون النقد والقرض 90-10 بالأمر الرئاسي 03-

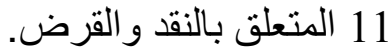
- - تحليل النتائج الكلية للقطاع خلال الفترة التي تلت تطبيق الأمر 03-11 وتحديدا القترة 2004-2008. - - - تحليل الأداء التنافسي للوحدات البنكية محل الدراسة خلال فترة تطبيق الأمر $.11-03$

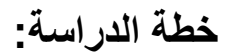

للإجابة على الإشكالية الرئيسية والأسئلة الفرعية المفسرة لها واختبار الفرضيات الموضو عة اقترحنا خطة العمل التالية:

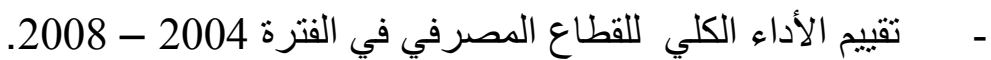
- - ـ - هيكل السوق وعلاقته بالربحية في الجهاز المصرفي الجزائري في ظل قانون $.11-03$

- مبيق نموذج Dupond على البنوك عينة الدراسة في الفترة 2004 .2008

تجدر الإشارة إلى أن البيانات المعتمدة في هذه الدراسة هي بيانات عينة من البنوك

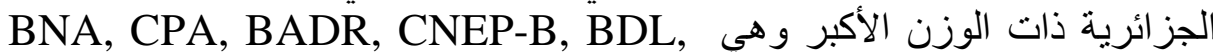
BARAKA

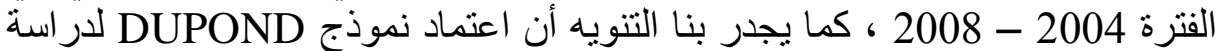

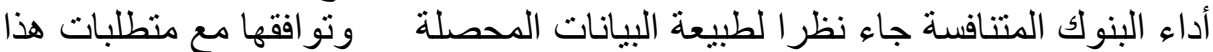

\section{أولا : تقييم الأداء الكلي للقطاع المصرفي الجزائري في الفترة 2004 - 2008} يعبر تقييم الأداء الكلي للقطاع المصرفي (السوق المصرفية) عن مدى توافق التشريع المطبق و الموضوع من قبل السلطة النقدية مع منطلبات السوق من حيث آليات 


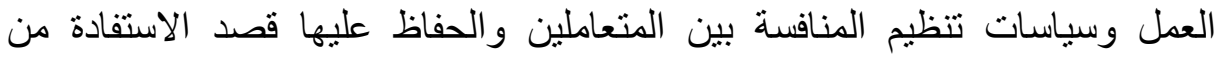

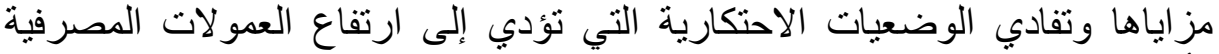

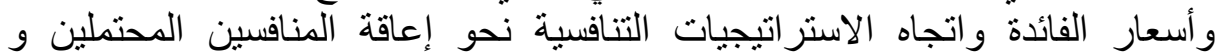
ابتعادها عن الابتكار وتحسين خدمة العملاء.

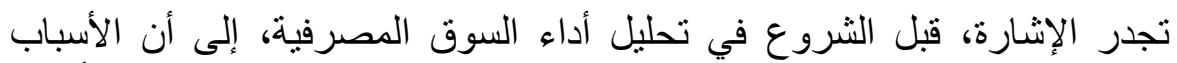

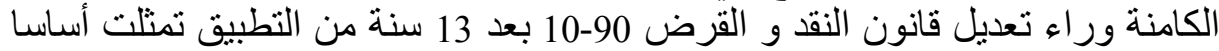

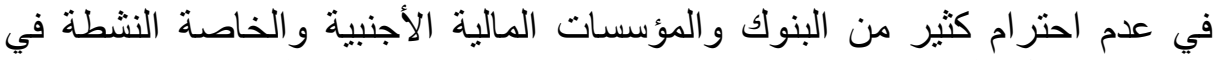

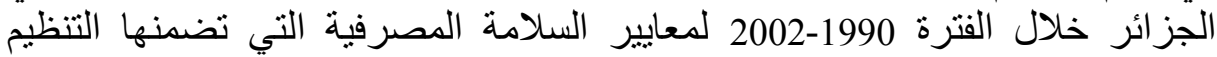

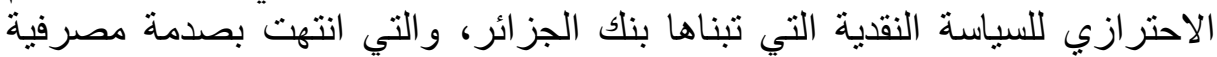

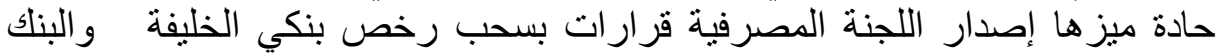

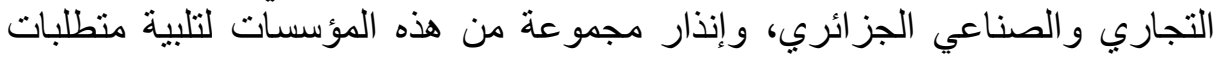

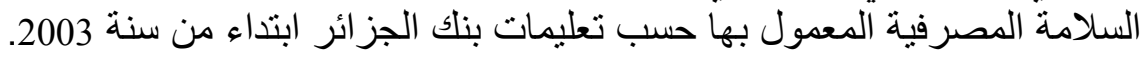

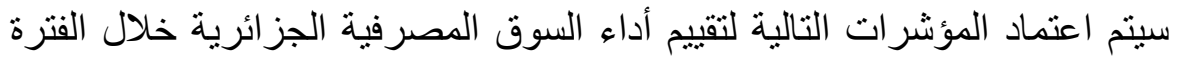

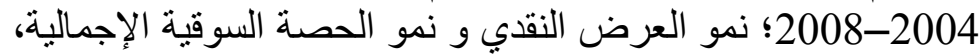

$$
1 \text { - نمو المعروض النقدي : }
$$

لمعرفة درجة نمو المعروض المعاض النقدي في السوق المصرفية الجزائرية خلال الفترة

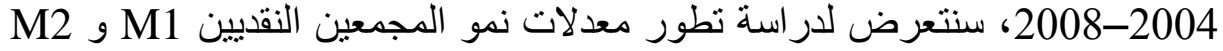
باعتبار أنها يضمان الودائع الجارية و الودائع الآجلة التي تتحكم البنوك في في تغير اتها

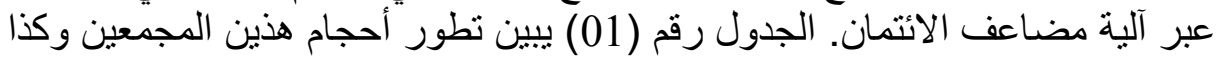
معدلات نمو هما السنوية عبر الفترة 2004-2008.

$$
\text { الجدول رقم (1) : تطور العرض النقدي خلال الفترة } 2004 \text { - } 2008
$$

\begin{tabular}{|c|c|c|c|c|c|}
\hline 2008 & 2007 & 2006 & 2005 & 2004 & السنو ات \\
\hline 3710.3 & 3322.5 & 2766.5 & 2422.7 & 2160.5 & M1 \\
\hline 11.67 & 20.10 & 14.19 & 12.14 & 32.51 & نمو M1 \% \\
\hline 6519.6 & 5517.3 & 4337.6 & 4164.9 & 3738.0 & M2 \\
\hline 18.17 & 27.20 & 4.15 & 11.42 & 11.44 & نمو M2 M2 \\
\hline
\end{tabular}
الوحدة : مليون دج الفي خلوب

المصدر: سحنون عقبة "المنافسة في الجهاز المصرفي الجزائري من خلال قوانين النقا

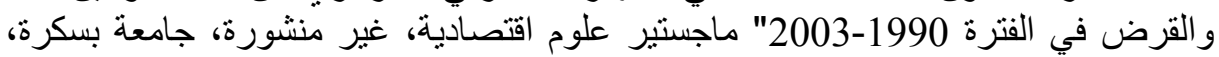
2009، ص في الفنرة 183.

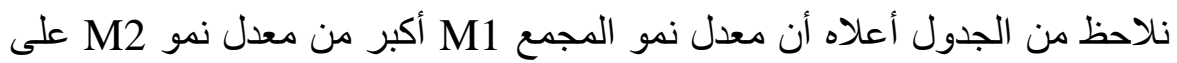

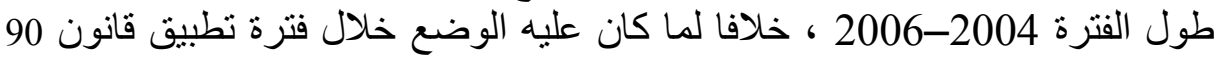

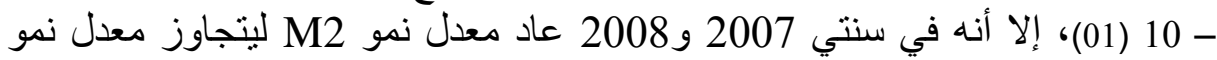
وبلغ معدل النمو السنوي المتوسط للنقود M1 نسبة 14.48 \% مقاد مقابل نمو 


$$
\text { منوسط لـ M2 بلغ معدله } 14.92 \text { \% سنويا. }
$$

تدل معدلات النمو المرتفعة للنقود M1 على ارتفاع السيولة لدى المصارف

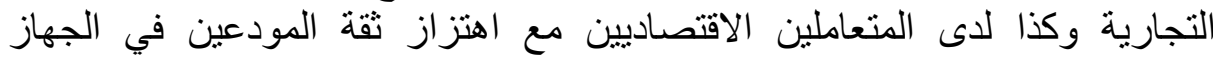

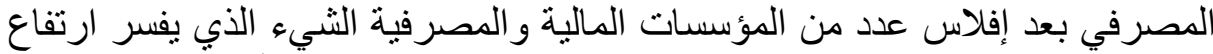

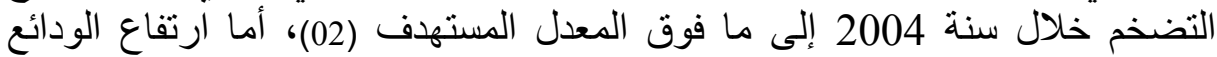

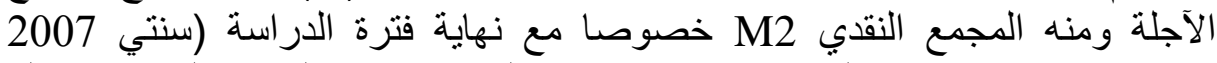

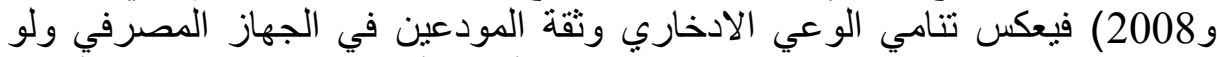

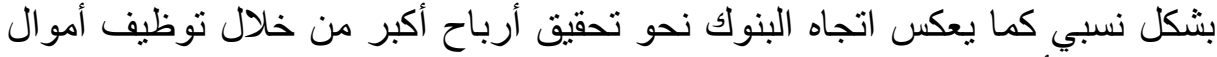

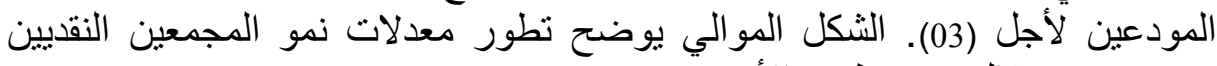

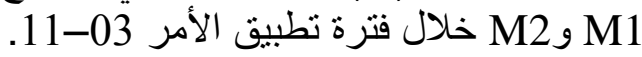

الشكل رقم (1) : تطور معدلات نمو المجمعين M1 و M2 خلال الفترة 2004 -

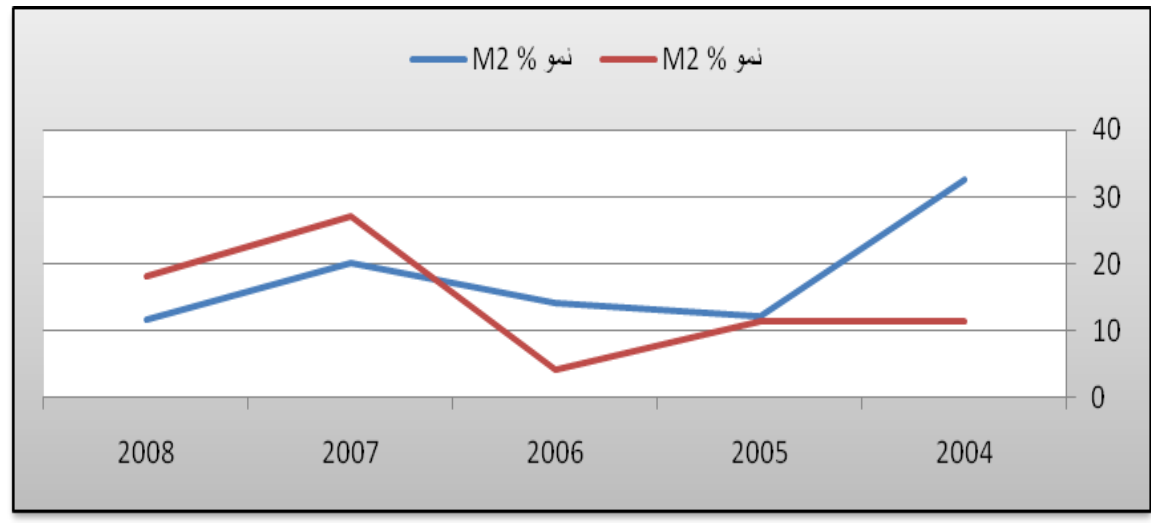

المصدر : من إعداد الباحثين اعتمادا على الجدول (1).

2 - نمو الحصة السوقية الإجمالية:

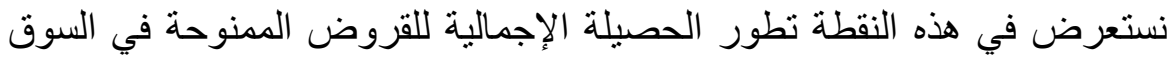

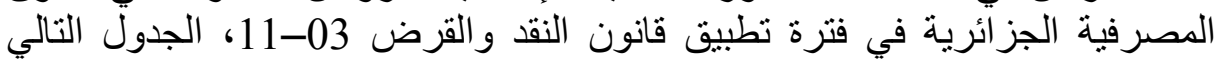
يوضح ذلك بالتفصيل.

الجدول رقم ( 2 ) : تطور الحصة السوقية الإجمالية في الفترة 2004 - 2008 الوحدة : مليار دجة الاحتة

\begin{tabular}{|c|c|c|c|c|c|}
\hline 2008 & 2007 & 2006 & 2005 & 2004 & السنو ات \\
\hline 1338.0 & 1201.1 & 919.3 & 839.0 & 1514.4 & السوقية الحصة \\
\hline
\end{tabular}




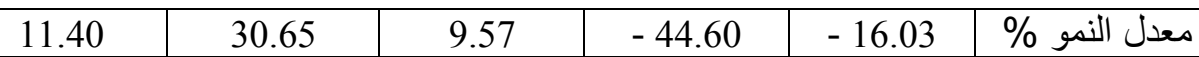

المصدر: إعداد الباحثين اعتمادا على: الطيب ياسين "الكفاءة المصرفية في البنوك

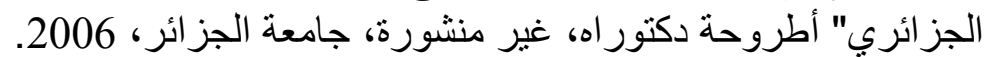

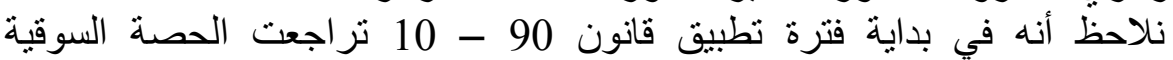
الإجمالية للصناعة المصرفية في الجز ائر من

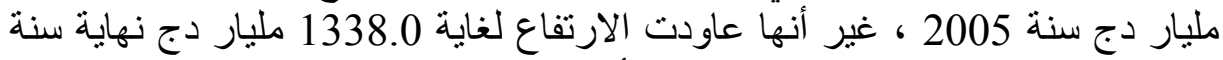

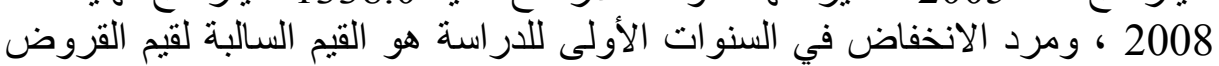

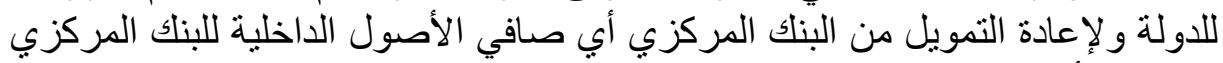

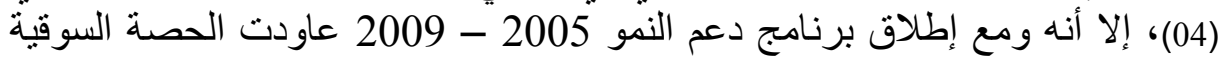

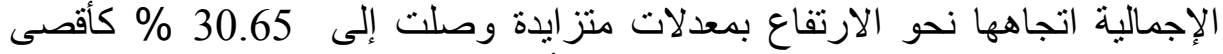

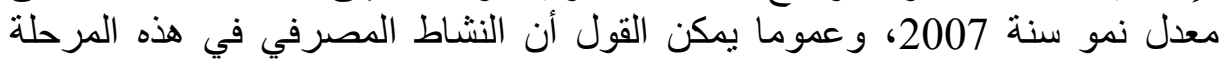

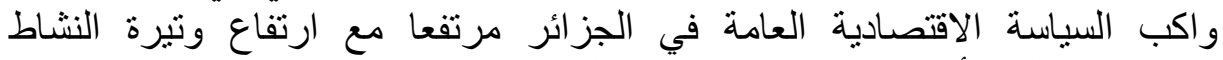

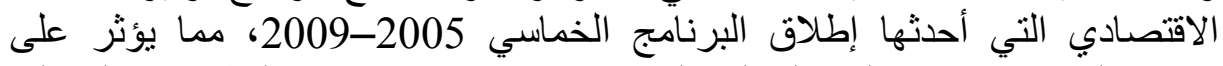

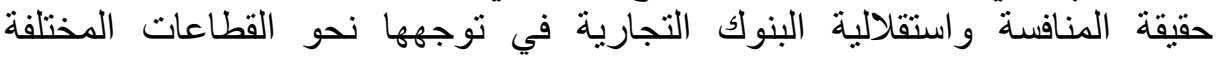

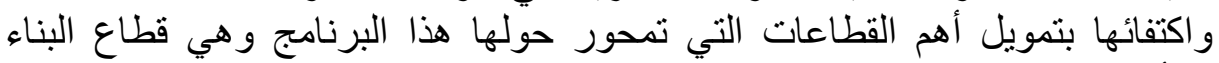

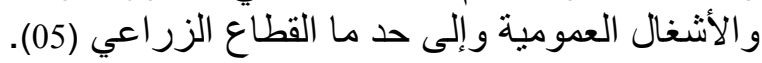

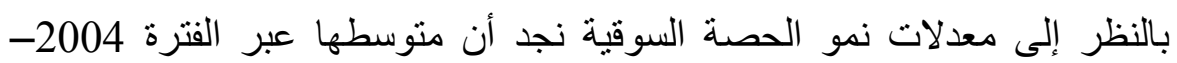

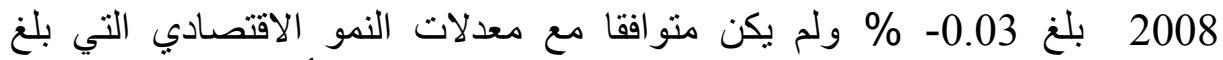

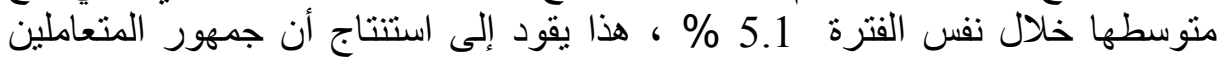

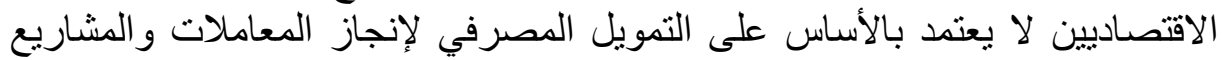

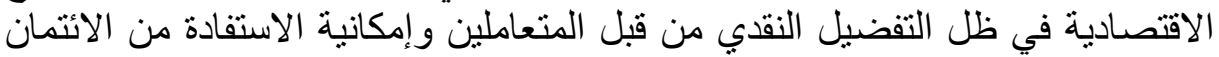

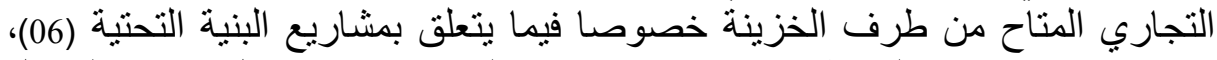

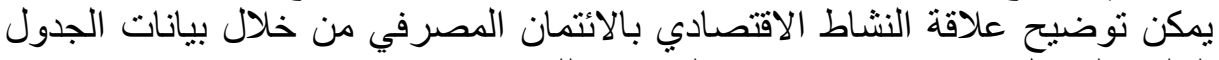
التالي: الجدول رقم (3) : مضاعف القروض للفترة 2004 - 2008 الوحدة: عدد المرات

\begin{tabular}{|c|c|c|c|c|c|}
\hline 2008 & 2007 & 2006 & 2005 & 2004 & السنوات \\
\hline 6.67 & 7.05 & 8.71 & 8.96 & 4.05 & Multi Crédit \\
\hline
\end{tabular}

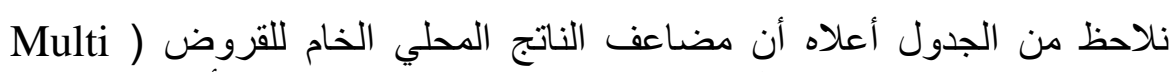
(Crédit

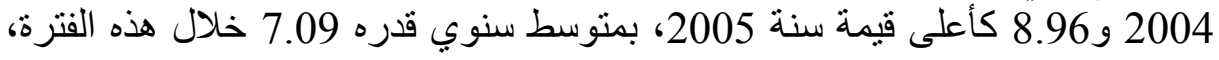

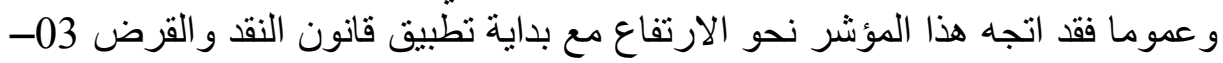
11 ثم عاود الانخفاض ليستقر سنة 2008 عند 6.67.

وبمقارنة النتائج مع ما كانت عليه من قيم مضاعف القروض خلال فترة تطبيق 
قانون 90-10 نجد أن قيم هذه الفترة كانت أقل مما هي عليه الآن ، أي أن الفجوة

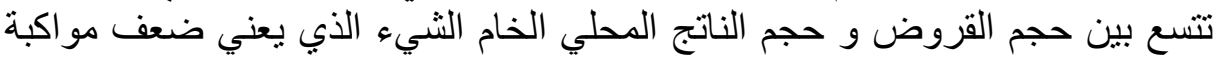

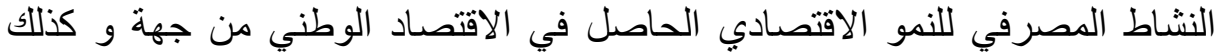
الطبيعة الهيكلية للاقتصاد الجزائري المعتمد بالأساس على الاسلى العائدات النفطية التي

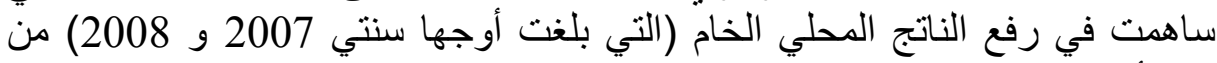
جهة أخرى (07).

\section{ثانيا : هيكل السوق وعلاقته بالربحية في الجهاز المصرفي الجزائري في ظل}

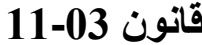

نحاول فيما يأتي معرفة تأثير هياكل السوق المصرفية على ربحية القطاع

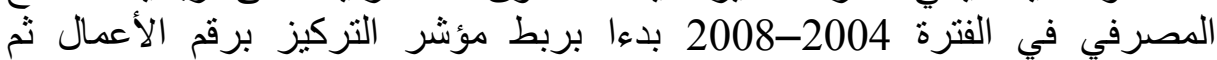
الاطلاع على علاقة عوائق الدخول بربحية السوق المصرفية.

$$
1 \text { - علاقة التركيز برقم الأعمال في الفترة } 2004 \text { - } 2008 \text { : }
$$

يفترض أن تكون العلاقة بين مؤشر التركيز ورقم الأعمال طردية، نظريا يعكس

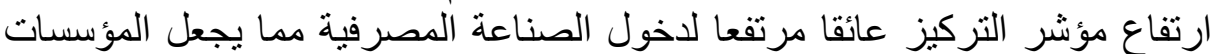

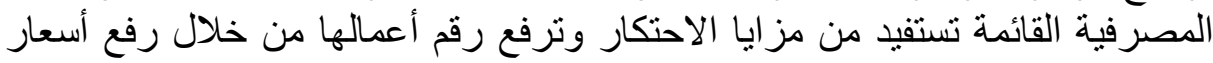

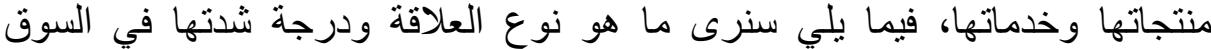

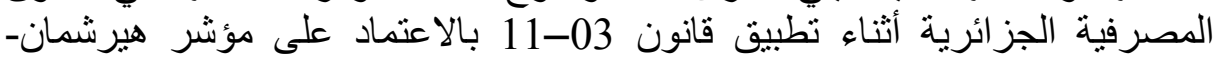

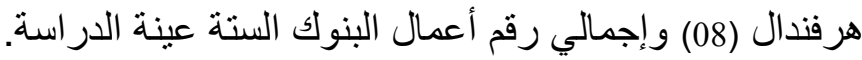

الجدول رقم (4) : العلاقة بين مؤشر التركيز ورقم الأعمال للبنوك الستة عينة

$$
\text { الدراسة 2004 - 2008 }
$$

\begin{tabular}{|c|c|c|c|c|c|}
\hline 2008 & 2007 & 2006 & 2005 & 2004 & السنو ات \\
\hline 21.5 & 21.6 & 27.8 & 21.4 & 21.3 & $(\%) \mathrm{H}$ \\
\hline 2019692 & 1974507 & 1948406 & 1769923 & 1685690 & قم الأعمال الإجمالي \\
\hline
\end{tabular}

$$
\text { المصدر : من إعداد الباحثين اعتمادا على الجدول (3) والجدول (4) . }
$$

من خلال تحليل بيانات الجدول أعلاه بواسطة تقنية الانحدار الخطي لرقم الأعمال

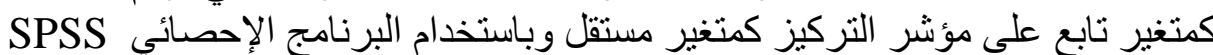

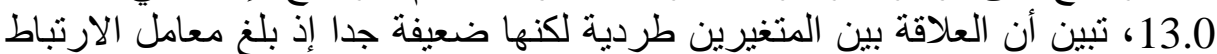

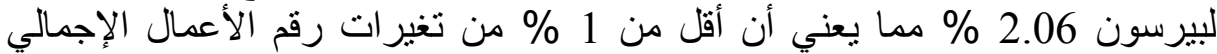
مردها إلى مؤشر التركيز أما بقية التغيرات أي 99 \% فمردها إلى عوامل أخرى غير الإن الإن

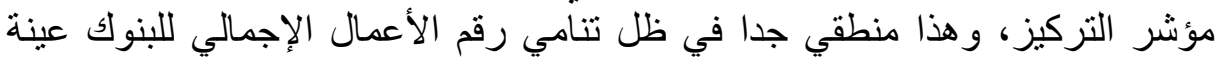

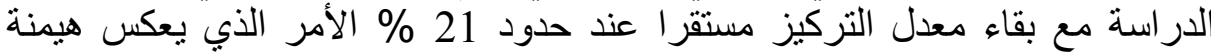

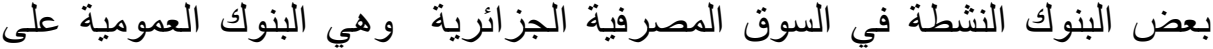
أغلب الحصة السوقية المصرفية التي يحسب على أساسها مؤشر التركيز. 


\section{2 - تأثثر عوائق الدخول على ربحية القطاع في الفترة 2004 - 2008 :}

في هذا البند سنحاول معرفة مدى مساهمة ارتفاع عوائق دخول السوق المصرفية

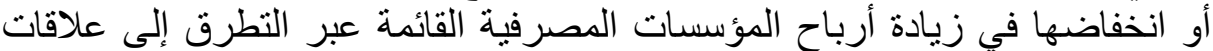

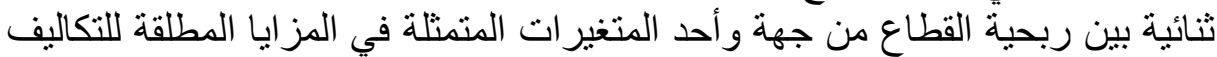
وتمييز المنتجات و سعر الحد من جهة ثانية؛

\section{2 ـ 1 - علاقة المزايا المطلقة للتكاليف بربحية القطاع المصرفي :}

من خلال دراستنا للتكاليف الخاصة بالبنوك عينة الدراسة تبين أنها كانت أكثر

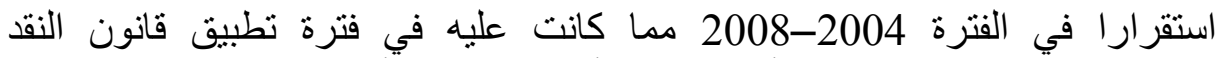
و القرض 90-10 (09)، فيما يأتي سنرى تأثثر ذلك على أرباح البنوك عينة الدراسة

الجدول رقم (5): تطور مؤشر التكاليف إلى رقم الأعمال و علاقته بربحية القطاع

$$
\text { المصرفي في الفترة } 1994 \text { - } 2003
$$

الوحدة : نسب مئوية

\begin{tabular}{|c|c|c|c|c|c|}
\hline 2008 & 2007 & 2006 & 2005 & 2004 & السنو ات \\
\hline-0.11 & -0.83 & 3.03 & 6.01 & 6.04 & تطور التكاليف \\
\hline 2.39 & 1.43 & 10.40 & 4.95 & 4.14 & تطور الأرباح \\
\hline
\end{tabular}

المصدر : من إعداد الباحثين اعتمادا على: سحنون عقبة، مرجع سبق ذكره، ص ص رل

من خلال تحليل البيانات بواسطة تقنية الانحدار الخطي بين معدل تطور الأرباح

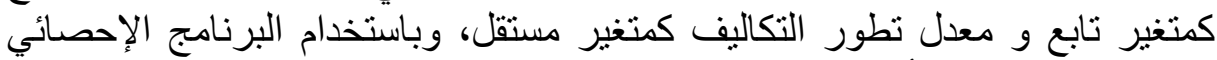

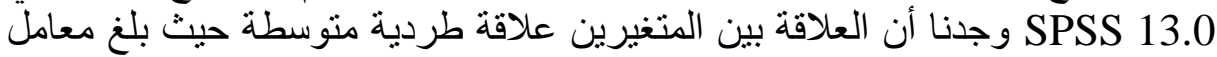

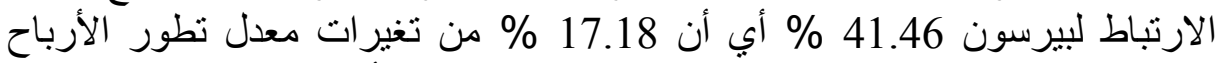
مرده التغير في معدل تطور التكاليف والباقي أن راجع لعوامل أخرى.

إن العلاقة الطردية بين المتغيرين تعني أن زيادة رقم الأعمال للبنوك عينة الدراسة

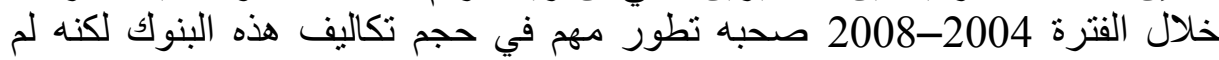

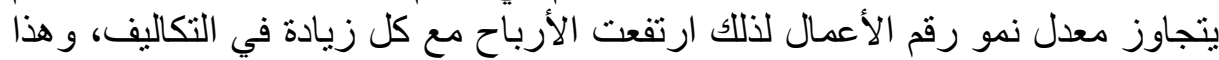

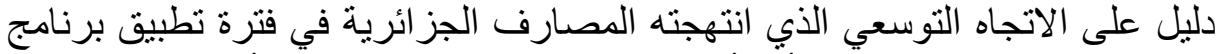
دعم النمو الاقتصادي (10)، أي أن التكاليف تمثلاث في تكاليف التهايف رأسمالية استثمارية وليست مجرد تكاليف استغلالية.

\section{2 ـ 2 ـ علاقة تمييز المنتجات بالربحية في الجهاز المصرفي :}

سنحاول فيما يلي ربط الإنفاق للبحث و التطوير بحجم الأرباح لمعرفة مدى مساهمة

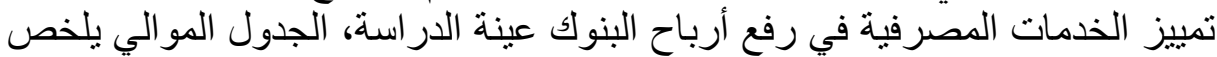


النتائج المحصلة.

الجدول رقم (6): تطور الإنفاق للتطوير و علاقته بالربحية في البنوك عينة الدر اسة

\begin{tabular}{|c|c|c|c|c|c|}
\hline & & & وحده : مليو & 200 & 200 \\
\hline 2008 & 2007 & 2006 & 2005 & 2004 & السنو ات \\
\hline 17019.158 & 38825.442 & 35172.852 & 23306.880 & 13866.395 & للالبحث \\
\hline 1941732 & 1896463 & 1869707 & 1693538 & 1613636 & إنجمالي \\
\hline
\end{tabular}

المصدر :من إعداد الباحثين اعتمادا على الجدول (5) و المرجع السابق، ص ص 196.

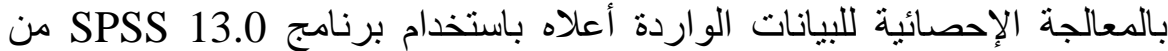

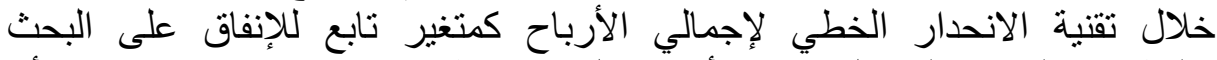

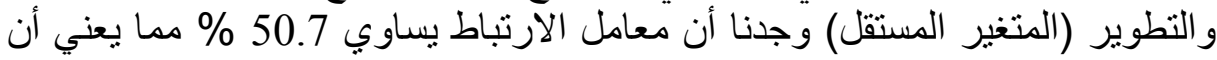

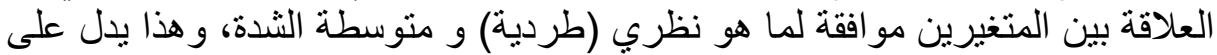

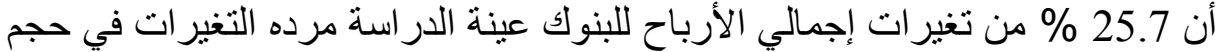

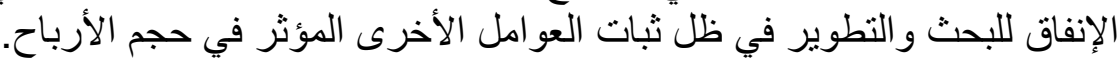

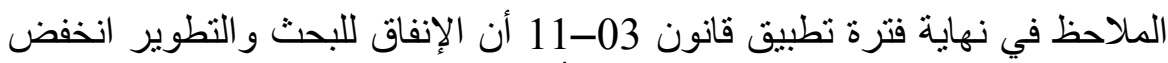

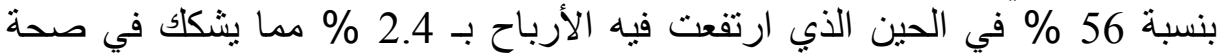
العلاقة بين المتغيرين من جهة ومن جهة أخرى يرجع الارتفاع الكبير في حجم الإح الإنفاق

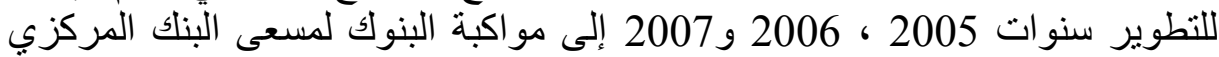
في تركيب و تشغيل نظامي ARTS و ATCI للتسوية الفورية و المقاصة الإلكترونية

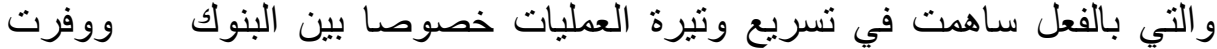
للبنولَّ إمكانية تحقيق أرباح في مدة زمنية أقل (11).

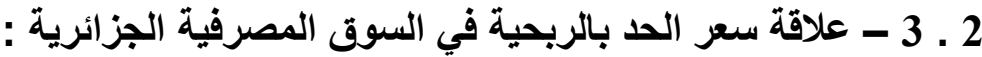

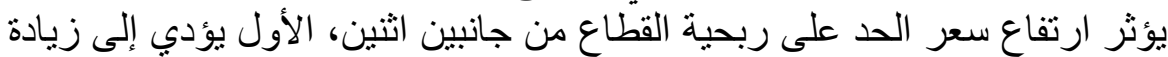

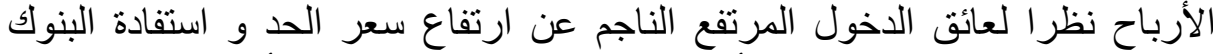

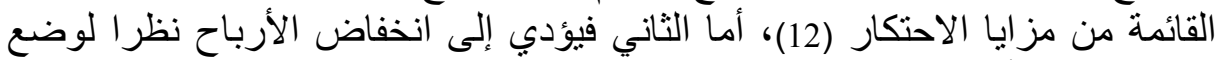

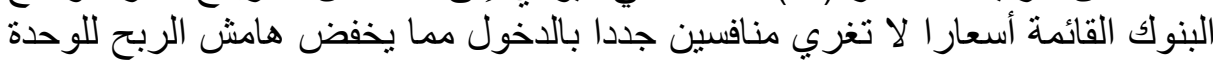

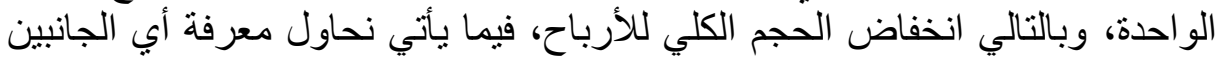

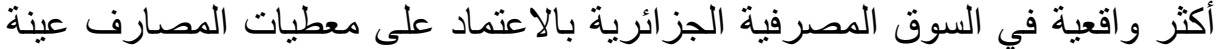

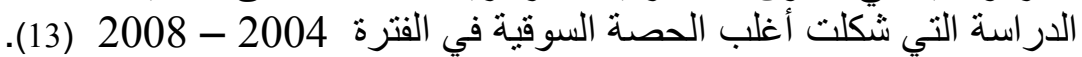
الجدول رقم (7) : علاقة سعر الحد بالأرباح في السوق المصرفية 2004 الوحدة : مليون دج 2008

\begin{tabular}{|l|l|l|l|l|l}
\hline 2008 & 2007 & 2006 & 2005 & 2004 & السنو
\end{tabular}




\begin{tabular}{|c|c|c|c|c|c|}
\hline 3.86 & 3.95 & 4.04 & 4.32 & 4.27 & $\%$ سعر الحمالي الأرباح \\
\hline 1941732 & 1896463 & 1869707 & 1693538 & 1613636 & إلداح \\
\hline
\end{tabular}

المصدر:من إعداد الباحثين اعتمادا على الجدول (6) و: الطيب ياسين، مرجع

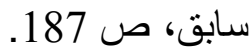

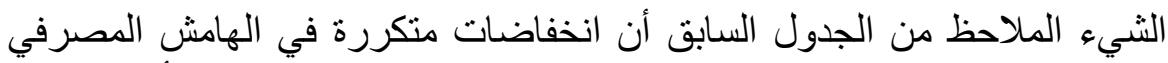

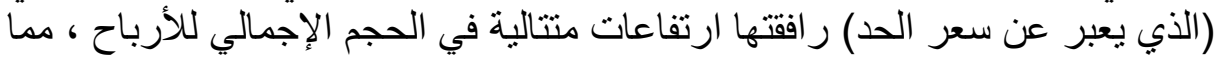
يوحي بوجود علاقة عكسية بين المتغيرين.

باستخدام تقنية الانحدار الخطي عبر البرنامج 13.0 SPSS بين حجم الأرباح

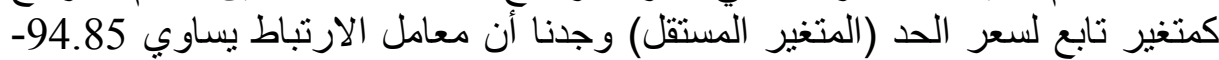

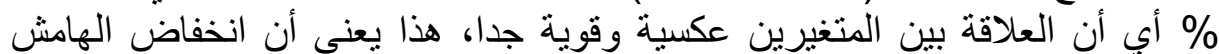

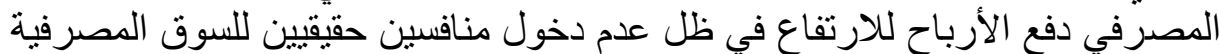

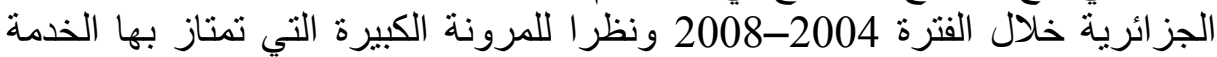

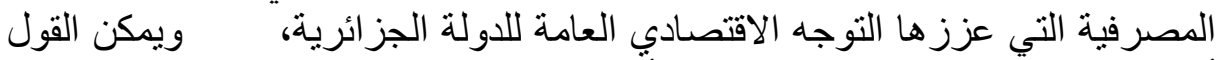
أن 90 \% من تغير ات الحجم الكلي للأرباح مردها التغير في سعر الحد بلتئة التئة قدرها \% 95

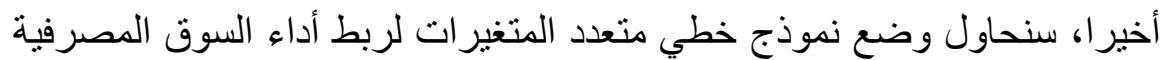

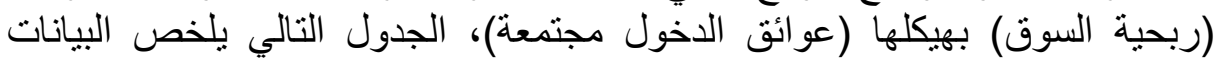
اللازمة لذلكة الكوف

\begin{tabular}{|c|c|c|c|c|c|}
\hline 2008 & 2007 & 2006 & 2005 & 2004 & السنو ات \\
\hline 77960 & 78044 & 78699 & 76385 & 72054 & TC \\
\hline 17019.158 & 38825.442 & 35172.852 & 23306.880 & 13866.395 & INOVA \\
\hline 3.86 & 3.95 & 4.04 & 4.32 & 4.27 & P Limite \\
\hline 1941732 & 1896463 & 1869707 & 1693538 & 1613636 & الإجماح لم \\
\hline
\end{tabular}

المصدر : من إعداد الباحثين اعتمادا على الجداول (6 )•(7).

بمعالجة البيانات أعلاه بواسطة البرنامج الإحصائي 13.0 SPSS عن طريث استخدام تقنية الانحدار المتعدد بين حجم التكاليف و مخصصات الإن التصات التطوير وسعر الحد كمتغير ات مستقلة و بين الحجم الإجمالي لأرباح البنوك عينة الدئ الدراسة كمتغير تابع لها تحصلنا على النموذج الموالي (14):

Bénéfices $=1802542+26.309$ TC -1.3 INOVA -483764 P.LIMITE

t ( 11.694$)(16.847)(-4.179)(-35.122)$ 


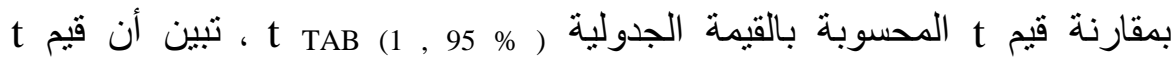

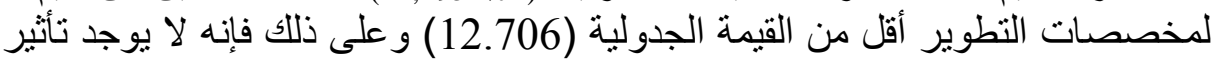
معنوي لمخصصات التطوير على الأرباح الإجمالية في السوق المصرية العرفية خلال الفترة 2004 - 2008 وبلغت قيمة الاحتمال 0.15، و يمكن حذف هذا المتغير من النموذج. بعد إجر اء التعديلات اللازمة تحصلنا على النموذج التالي :

Bénéfices $=1894329+33002$ TC -445089 P.LIMITE

$$
\text { t (14.069) (22.901) (21.227) }
$$

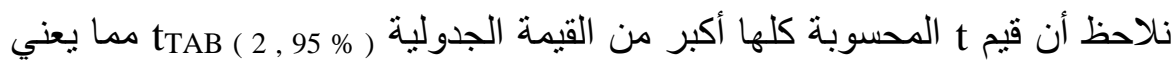

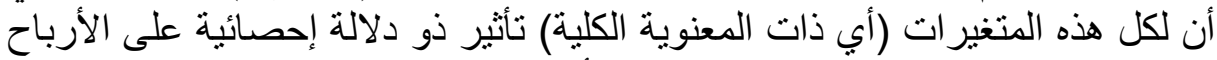

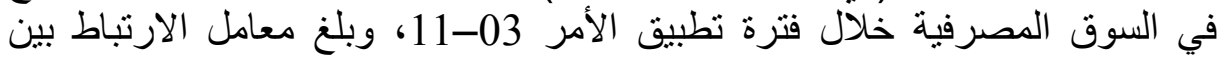

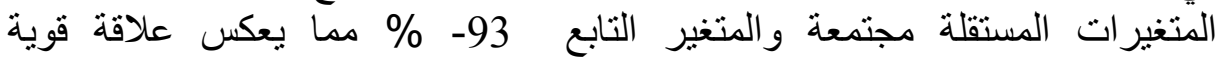
و عكسية بين التكاليف الكلية وسعر الحد وبين حجم الربح الإجمالي أي أن 86.5 \%

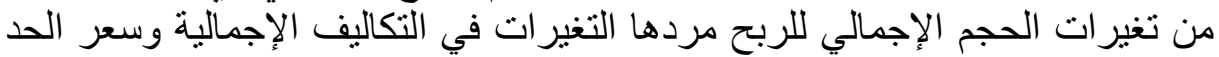

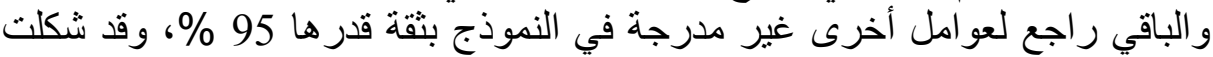
التكاليف الكلية 22 \% من معامل الارتباط بينما شكل سعر الحد 78 \% \% الباقية، وقدر الخطأ المعياري بـ 51,09 مليون دج و يعتبر هذا مقبولا في ظلا فل القيم الكبيرة للهامش المصرفي المقدر بآلاف ملايير الدينار.

\section{ثالثا : تطبيق نموذج Dupond على البنوك عينة الدراسة في الفترة 2004 - 2008} لمعرفة أثر السلوك الاستراتيجي التنافسي للبنوك العاملة في القطاع المصرفي

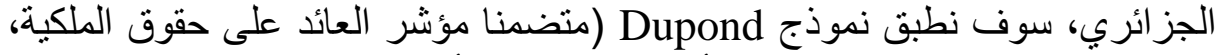

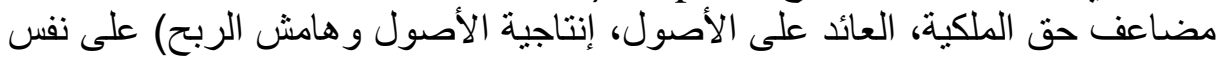

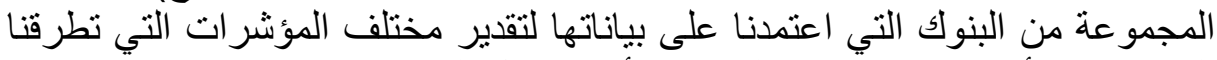
إليها باعنبار أنها تمنلك الحصة السوقية الأكبر خلال الفترة 2004-2008.

1 - العائد على حقوق الملكية ROE: فيما يلي سنرى أي البنوك من ضمن عبنة

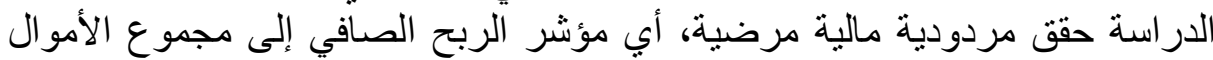

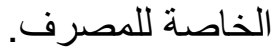
الجدول رقم (9) : العائد على حقوق الملكية ROE في الفترة 2004 - 2008

\begin{tabular}{|c|c|c|c|c|c|c|}
\hline المتوسط & 2008 & 2007 & 2006 & 2005 & 2004 & السنو ات \\
\hline 2.935 & 3.344 & 4.385 & 1.749 & 2.412 & 2.786 & BNA \\
\hline 5.493 & 11.310 & 3.584 & 4.716 & 2.017 & 5.836 & CPA \\
\hline 6.012 & 12.584 & 1.074 & 2.776 & 8.234 & 5.390 & BADR \\
\hline 2.531 & 6.232 & 0.394 & 2.359 & 3.059 & 0.610 & BDL \\
\hline
\end{tabular}




\begin{tabular}{|r|r|r|r|r|r|c|}
\hline 2.458 & 1.201 & 2.484 & 5.635 & 1.768 & 1.204 & CNEP-B \\
\hline 32.470 & 40.675 & 29.011 & 21.190 & 39.46 & 32.014 & BARAKA \\
\hline
\end{tabular}

المصدر : من إعداد الباحثين اعتمادا على ميز انيات البنوك عينة الدراسة .

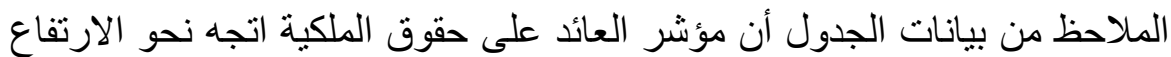

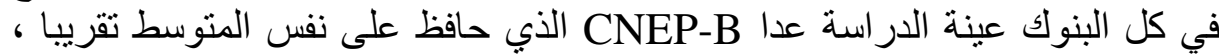

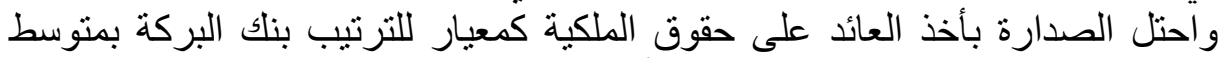

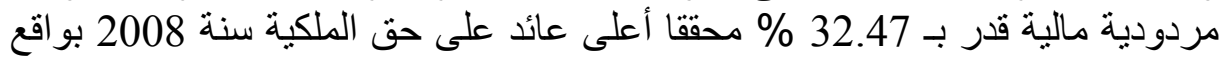

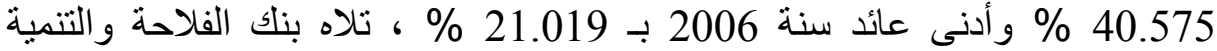
الريفية BADR بمتوسط مردودية مالية مقداره 6.012 \% بعدما احتل المرتبة

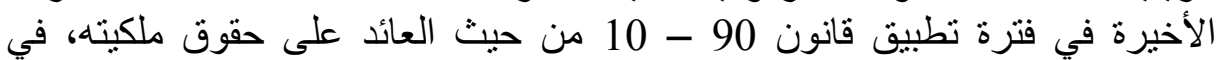
المرتبة الثالثة جاء بنك CPA الذي ارتفع منوسط عائده على حقوق الملكية من 2 \% في الفترة 1994 - 2003 إلى 2.935 \% 5.493 \% في الفترة 2004 - 2008، بعده بناء بنك

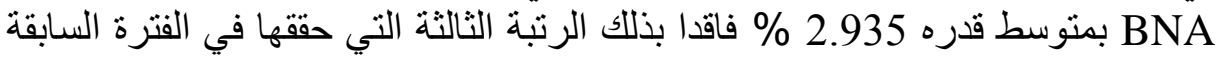

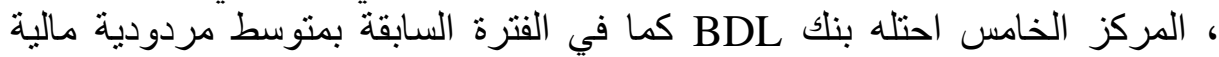

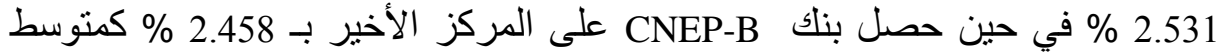
مردودية مالية خلال فترة تطبيق الأمر 03 - 11 (15) .

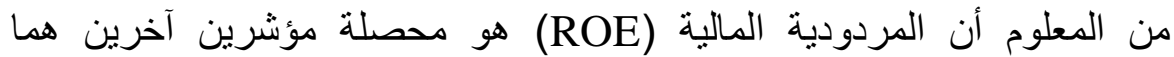

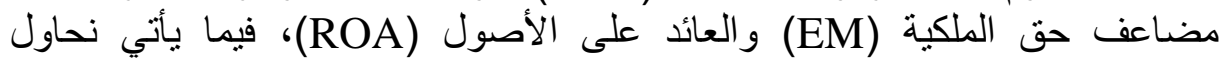
الإطلاع على أي المؤشرين ساهم بنسبة أكبر في رفع العائد على حقوق الملكية.

2 - مضاعف حق الملكية EM : مضاعف حق الملكية هو معكوس ذراع الر افعة

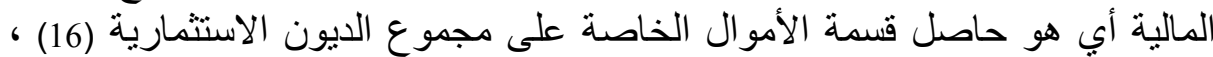
الجدول ألموالي يوضح تفصيل هذا المؤشر لكل البنوك عينة الدراسة خلانل الإل الفترة 2008-2004

الجدول رقم (10) : نطور مضاعف حق الملكية في البنوك عينة الدراسة خلال الفترة 2004 - 2004 مثن

\begin{tabular}{|r|r|r|r|r|r|r|}
\hline المتوسط & 2008 & 2007 & 2006 & 2005 & 2004 & السنو \\
\hline 14.995 & 13.703 & 17.129 & 15.902 & 15.971 & 12.268 & BNA \\
\hline 12.862 & 15.534 & 11.096 & 13.870 & 12.609 & 11.202 & CPA \\
\hline 14.008 & 15.809 & 15.348 & 13.158 & 13.476 & 12.251 & BADR \\
\hline 14.681 & 13.578 & 13.140 & 14.931 & 16.447 & 15.310 & BDL \\
\hline 13.006 & 13.195 & 14.115 & 14.411 & 11.945 & 11.363 & CNEP-B \\
\hline 6.203 & 5.819 & 6.775 & 5.678 & 5.798 & 6.943 & BARAKA \\
\hline
\end{tabular}

المصدر : من إعداد الباحثين اعتمادا على ميزانيات البنوك عينة الدراسة . 
الملاحظ من الجدول أعلاه أن مضاعف حت الملكية بقي مرتفعا في جميع البنوك

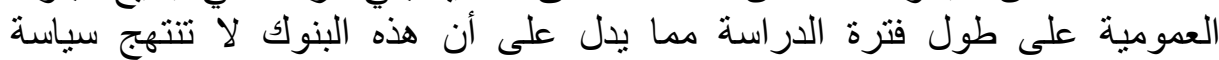

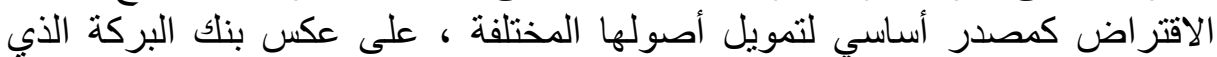

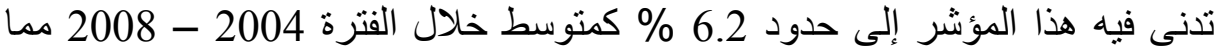

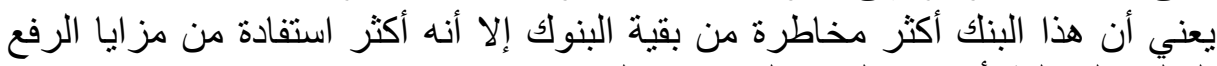

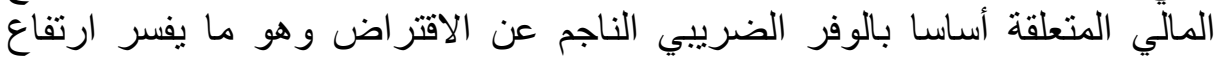

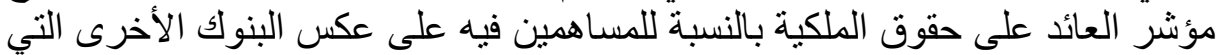

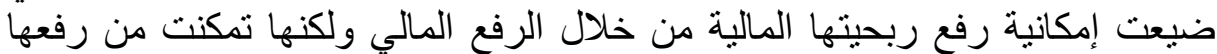

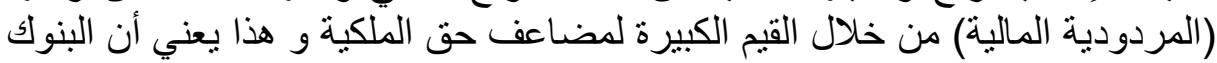

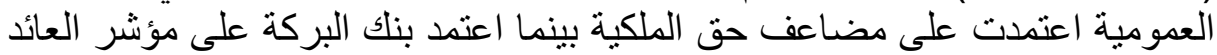
على الأصول لرفع العائد على حق الملكية (17)، هذا ما سنتأكد منه في النقطة الموالية.

\section{3 - ROA العائد على الأصول}

يعبر مؤشر العائد على الأصول عن كفاءة المصرف في إدارة أصوله لهوله (18) ،

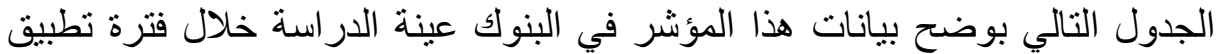

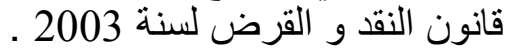

$$
\text { الجدول رقم (11): العائد على الأصول خلال الفترة } 2004 \text { - } 2008
$$
الوحدة : نسب مئوية

\begin{tabular}{|r|c|c|c|c|c|c|}
\hline المتوسط & 2008 & 2007 & 2006 & 2005 & 2004 & السنو \\
\hline 0.194 & 0.244 & 0.255 & 0.110 & 0.151 & 0.210 & BNA \\
\hline 0.414 & 0.728 & 0.323 & 0.340 & 0.160 & 0.521 & CPA \\
\hline 0.426 & 0.796 & 0.070 & 0.211 & 0.611 & 0.440 & BADR \\
\hline 0.175 & 0.459 & 0.030 & 0.158 & 0.186 & 0.040 & BDL \\
\hline 0.182 & 0.091 & 0.176 & 0.391 & 0.148 & 0.106 & CNEP-B \\
\hline 5.284 & 6.990 & 4.282 & 3.732 & 6.805 & 4.611 & BARAKA \\
\hline
\end{tabular}

المصدر : من إعداد الباحثين اعتمادا على ميز انيات البنوك عينة الدراسة .

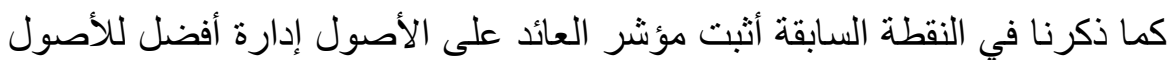

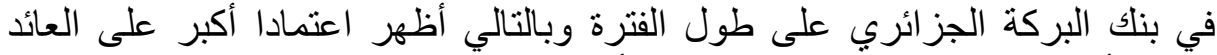
على الأصول (بلغ متوسط العائد على الأصول 5.3 \% ) لرفع مردوديته الئه المالية في

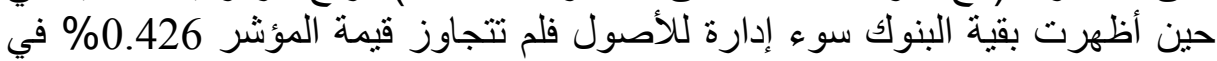

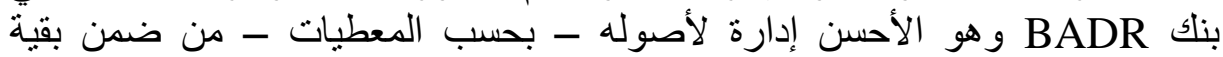
البنوك العمومية التي اعتمدت بشكل كبير على مضاعف حق لأل الملكية. 
وجاء ترتيب البنوك من الأحسن إلى الأسوأ حسب باتخاذ هذا المؤشر كمعيار

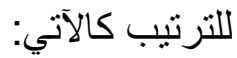

- بنك البركة في المرتبة الأولى بمتوسط عائد على الأصول 5.284\%؛

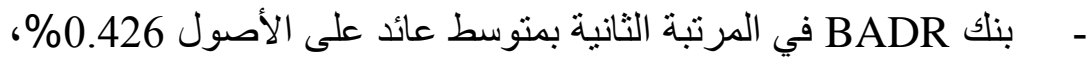

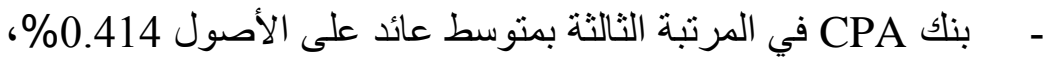

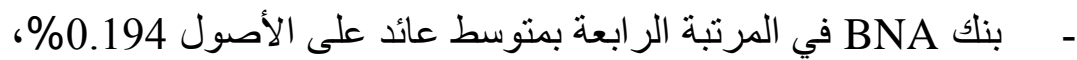

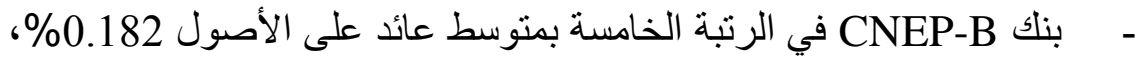

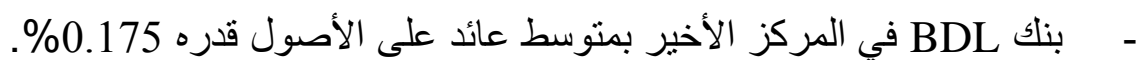

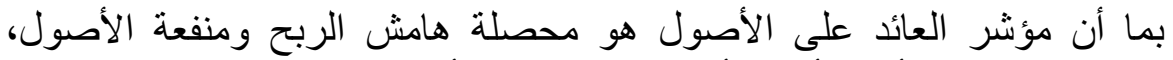

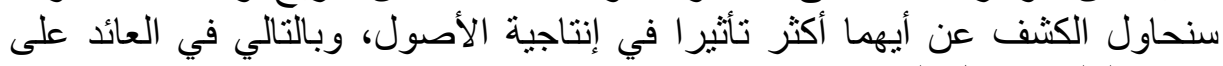

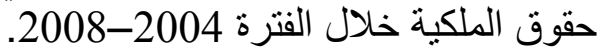

\section{: UA Uنفعة الأصول}

يعبر مؤشر منفعة الأصول عن مدى جودة الأصول التي تختارها المؤسسة،

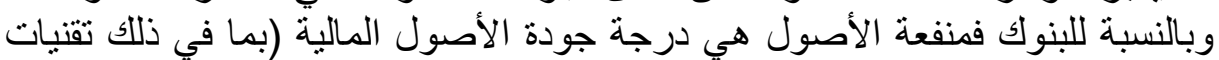
التمويل المعتمدة) التي تختار المؤسسة المصرفية الاستثمار فيها، الجدول الآتي يوضح قيم منفعة الأصول خلال الفترة الفئ 2004-2008.

الجدول رقم (12): تطور منفعة الأصول في البنوك عينة الدراسة في الفترة 2004 - 2008 -

\begin{tabular}{|c|c|c|c|c|c|c|}
\hline & & & & & \\
السنوسو & 2008 & 2007 & 2006 & 2005 & 2004 & (السنو \\
\hline 6.36 & 7.91 & 8.37 & 5.09 & 4.31 & 6.12 & BNA \\
\hline 11.53 & 19.30 & 6.44 & 8.83 & 9.18 & 13.90 & CPA \\
\hline 15.05 & 19.51 & 23.11 & 8.93 & 13.40 & 10.28 & BADR \\
\hline 6.85 & 10.85 & 13.23 & 4.94 & 4.33 & 0.91 & BDL \\
\hline 23.18 & 21.15 & 32.49 & 18.82 & 24.13 & 19.33 & CNEP-B \\
\hline
\end{tabular}




\begin{tabular}{|l|l|l|l|l|l|l|}
\hline 26.441 & 22.361 & 20.886 & 23.039 & 29.111 & 26.808 & BARAKA \\
\hline
\end{tabular}

المصدر : من إعداد الباحثين اعتمادا على ميزانيات البنوك عينة الدراسة .

على عكس فترة تطبيق قانون النقد و القرض 90-10 اتجهت مؤشرات منفعة

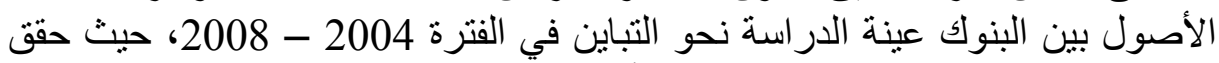
كل من البركة و CNEP-B منفعة أصول مرتفعة مقارنة ببقية المصارف في في الفئ 26.441\% و 23.18\% على التوالي في حين تقاربت قيم هذا المؤشر لاى BPA

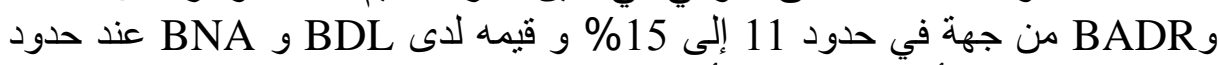
\% من مجموع الأصول من جهة أخرى.

5 - هامش الربح PM : يوضح الجدول التالي قيم مؤشر هامش الربح في البنوك عينة الدراسة في الفترة 2004-2008

الجدول رقم (13): هامش الربح في البنوك عينة الدراسة في الفترة 2004 -

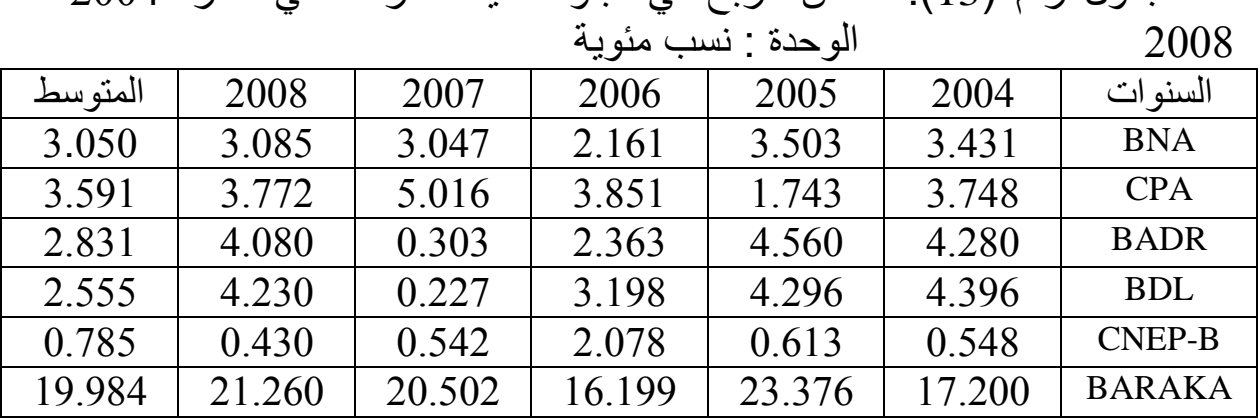

المصدر : من إعداد الباحثين اعتمادا على الجدول (11) و الجدول (12) .

الملاحظ أن هامش الربح كان متقاربا في جميع البنوك العمومية عند مستوى 3.

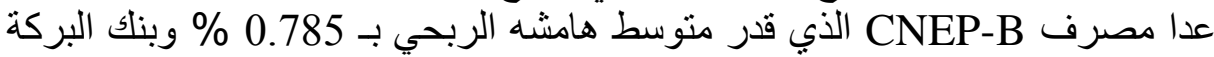
الذي حقق أكبر هامش ربحي منوسط بواقع 20\% تقريبا، والسبب في ذلك اختلاف

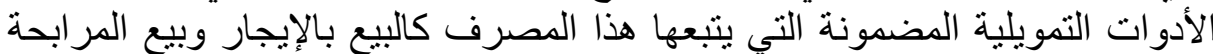

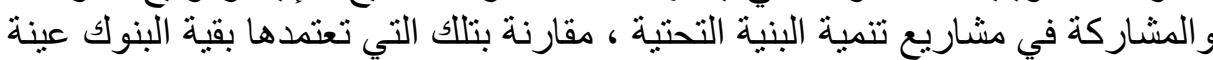

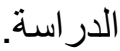

يمكن تلخيص النتائج المتوصل إليها من تطبيق نموذج Dupond من خلال النقاط

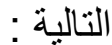

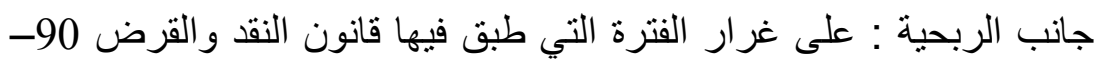

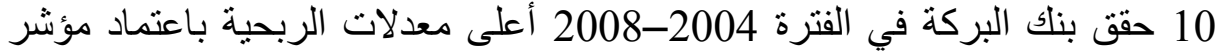

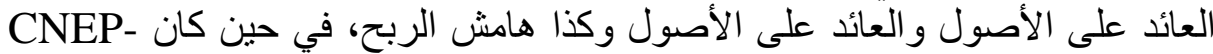

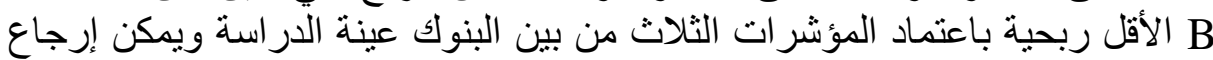


ذللك إلى الحجم الكبير الذي يميز البنك إضافة إلى تشكيلة المنتجات التي يقدمها و التي تتتلاءم أكثر مع كونه صندوقا للادخار قبل سنة 1998 (19).

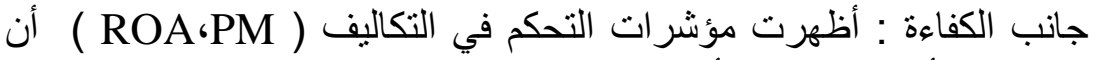

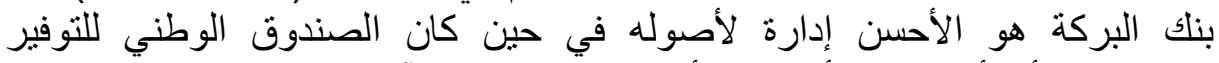
و الاحتياط الأسوأ في إدارة أصوله للأسباب التي ذكرناها آنفا.

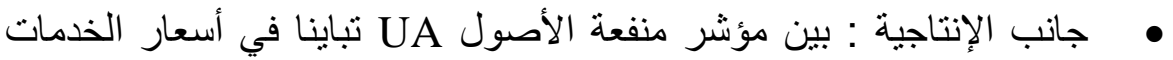

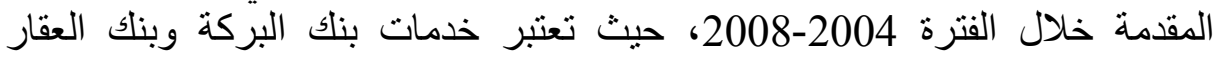
CNEP-B المنتجات المصرفية في السوق المصرفية الجزائرية ضيقة اللية للغاية بغياب المشتقات

المالية و النقدية فيها.

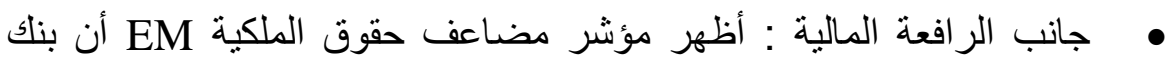

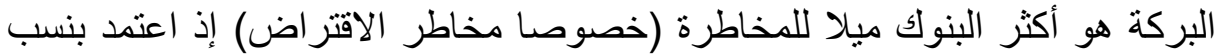

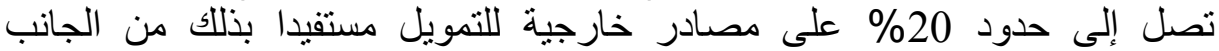
الإيجابي للرفع المالي، في حين أن البنوك العمومية بقيت متحفظة واستخدمت المبل أمو الها

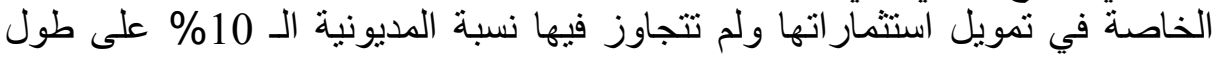
الفترة 2004 - 2008 مضيعة بذلك رفع ربحيتها عن طريق الاستفادة من مزايا الرفع المالي ومحققة جانب أمان مرتفع جدا يمكنها من الحفاظ على ولاء لاء عملائها في ظل وسطية تكاليف خدماتها (20).

الجدول الموالي يلخص ترتيب المصارف حسب كل مؤشر خلال فترة تطبيق قانون 03 -

\begin{tabular}{|c|c|c|c|c|}
\hline \multicolumn{5}{|c|}{ الجدول رقم (14 ) : ترتيب البنوك حسب معايير نموذج Dupond } \\
\hline الر افعة المالية & الإنتاجية & 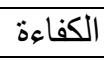 & 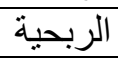 & المؤشر ات \\
\hline 1 & 6 & 6 & 4 & BNA \\
\hline 5 & 4 & 5 & 3 & CPA \\
\hline 3 & 3 & 4 & 2 & BADR \\
\hline 2 & 5 & 3 & 5 & BDL \\
\hline 4 & 2 & 2 & 6 & CNEP-B \\
\hline 6 & 1 & 1 & 1 & BARAKA \\
\hline
\end{tabular}

المصدر: من إعداد الباحثين اعتمادا على الجداول (9)، (01)، (11)،(12) و و)

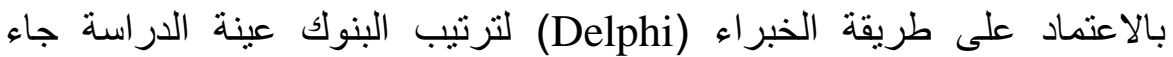

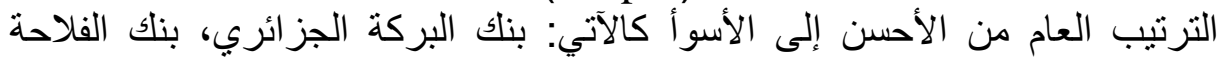

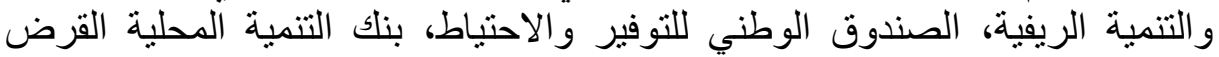


الثعبي الجزائري وأخيرا البنك الوطني الجزائري، بثقة قدر ها 80 \% (21). في الأخير، حاولنا استعر اض بعض النغ المؤشرات الصناعية ( الوسطية ) للسوق

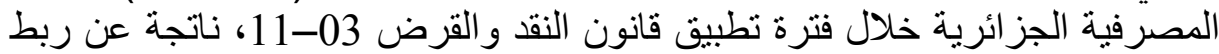

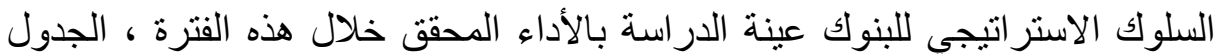
يوضح ذلك.

الجدول رقم(15): المتوسطات الصناعية لنموذج Dupond في الفترة 2004 - 2008 الوحدة : نسب مئوية

\begin{tabular}{|c|c|c|c|c|c|}
\hline ROE & EM & ROA & PM & UA & المؤشر أش \\
\hline 2.841 & 12.028 & 0.384 & 4.560 & 1.672 & 2004 \\
\hline 4.320 & 13.569 & 0.392 & 4.431 & 2.000 & 2005 \\
\hline 3.307 & 14.495 & 0.258 & 2.901 & 0.511 & 2006 \\
\hline 3.160 & 14.436 & 0.270 & 4.216 & 0.307 & 2007 \\
\hline 6.619 & 14.431 & 0.610 & 4.519 & 0.178 & 2008 \\
\hline
\end{tabular}

المصدر : من إعداد الباحثين اعتمادا على الجداول (9)، (01)، (11)، (12)

حتى يكون أداء البنوك أفضل من المنافسين لها في السوق المصرفية الجزائرية

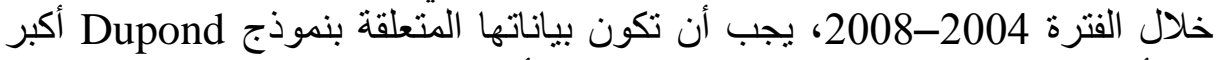

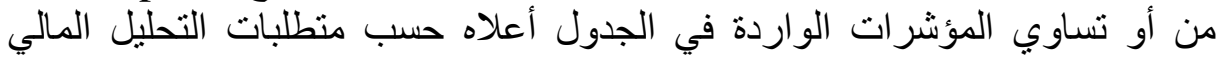

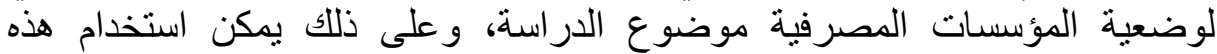

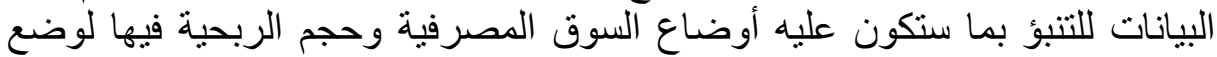

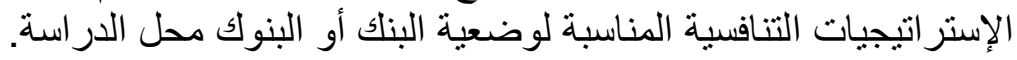

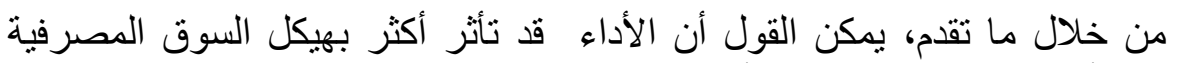

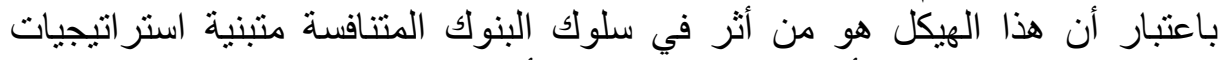

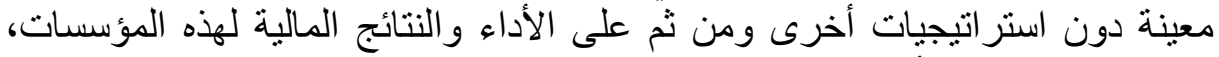

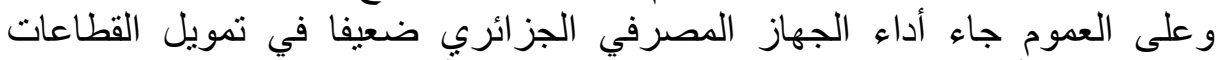

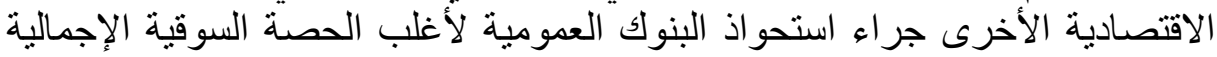
من جهة وضيق تشكيلة منتجاتها، و عدم استقلاليتها عن محاور الأنية السياسة المالية للخزينة

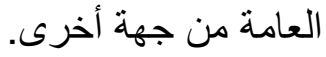




\section{الخاتمة}

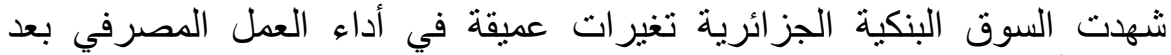

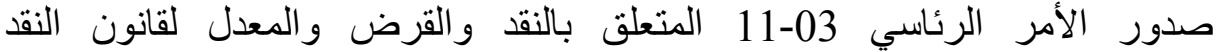

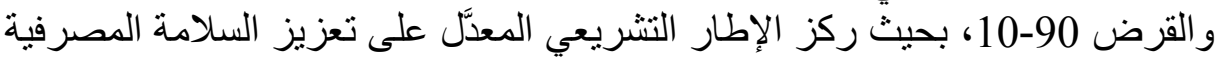

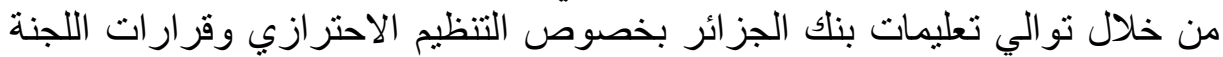

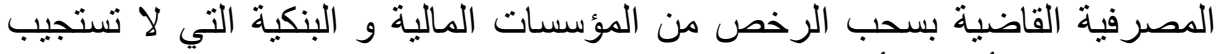
لشروط الحد الأدنى لرأس المال ولا تلتزم بتحقيق المعدلات المالية المقررة بموجب لالية هذه التعليمات.

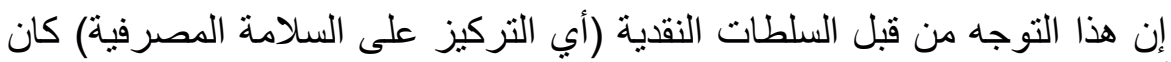

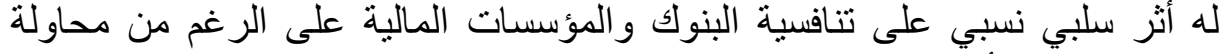
التحديث نسبيا لأداء الخدمات البنكية بتوفير البنية التحتية التكنولوجية و لوالية لو جزئيا عبر

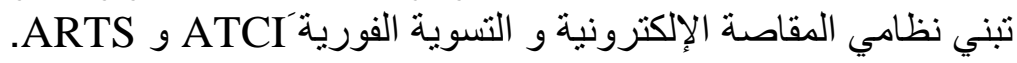

بالقياس الكمي لمختلف المتغيرات التي أوردناها في هذه الدراسة، تبين التين أن هيكل

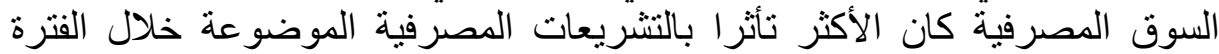

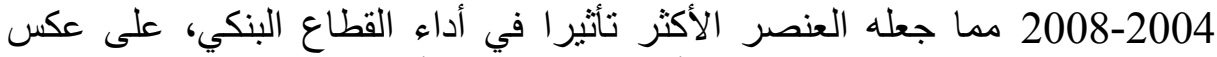

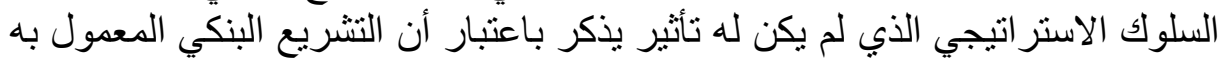
لم يوله اهتماما بذكر الانئري

بالنسبة لجانب اختبار الفرضيات الموضوعة، فقد أظهرت النتائج أن الفرضية

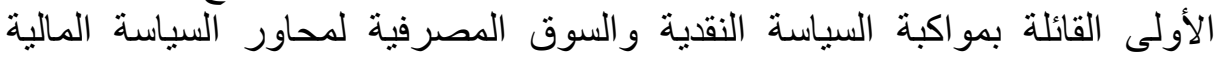

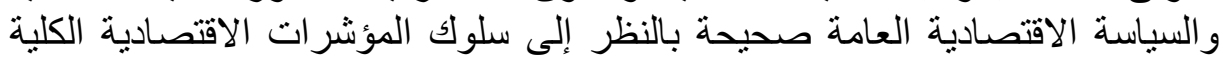

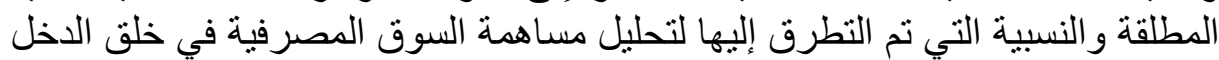

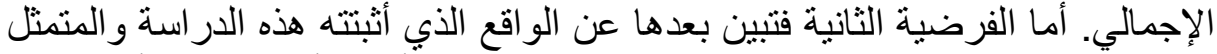

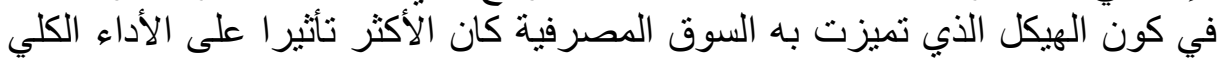

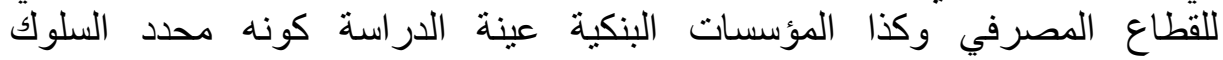

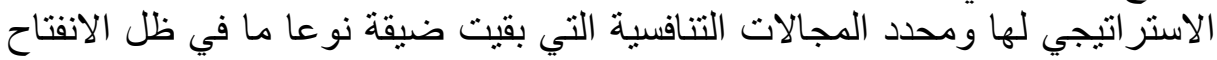

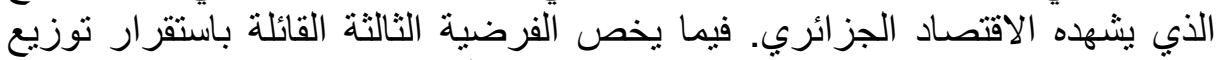
الحصص السوقية بين البنوك عينة الدراسة فقد تبين أنها صحيحة خصوصا من زاوية 


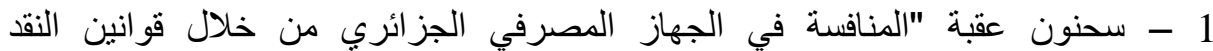
و القرض 90-10 و03-11" رسالة ماجستير غير منشورة في العلوم الاقتصسادية، جامعة النية

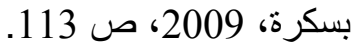

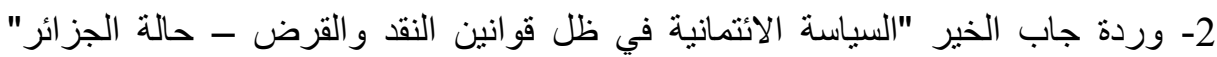

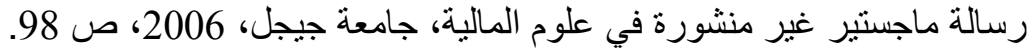

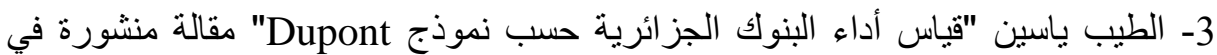

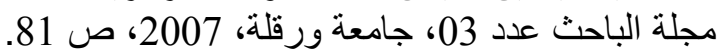

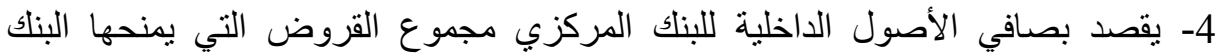

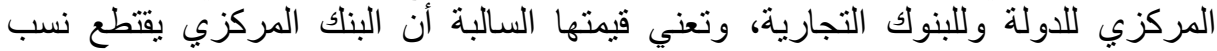

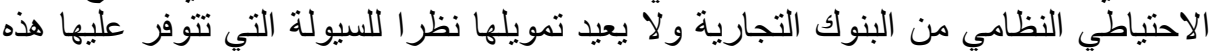

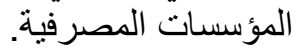
5- وزارة المالية: ملخص برنامج دعم النمو 2004-2009، منشورات وزارة المالية،

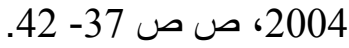
6- دار الملكية: الصفقات العمومية (قو انين وتنظيمات)، لملكية للطباعة والنشر و التوزيع

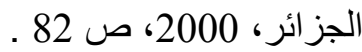

7- note de conjoncture $1^{\text {er }}$ trimestre 2009, éd banque d'Algérie,2009, pp 17-22.

8- يحسب مؤشر هيرشمان و هيرفندال بجمع مربعات القيم السوقية للبنوك المتنافسة الأكثر

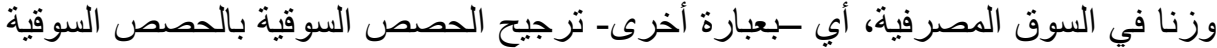

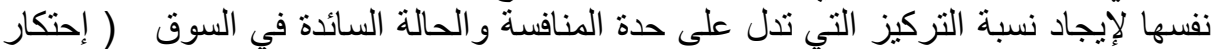

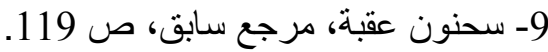

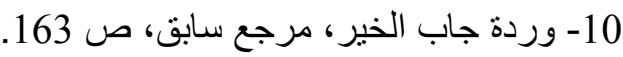

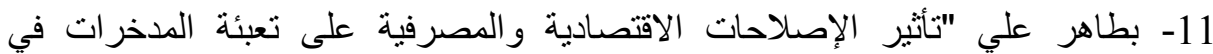

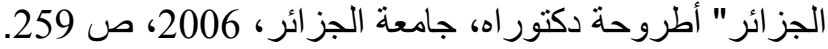

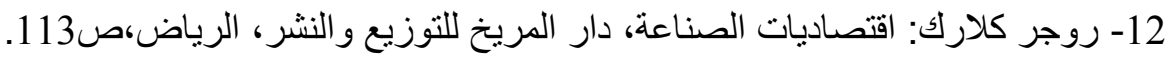

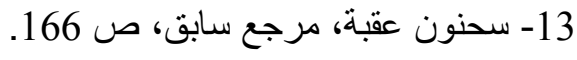


14- مخرجات برنامج SPSS13.0 بالاعتماد على تقنية الانحدار المتعدد. 15- محمد قريشي جموعي " قياس كفاءة المؤسسات المصرفية الجزائرية في الفترة 1994

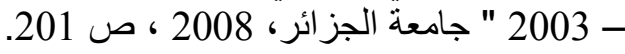

16- لرقم عبد الحفيظ: محاضرات في التحليل المالي الجزء الثاني، منشورات جامعة

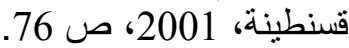

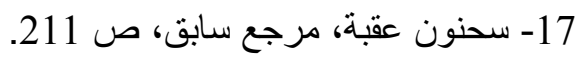

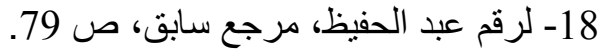

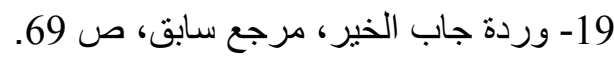

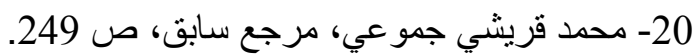

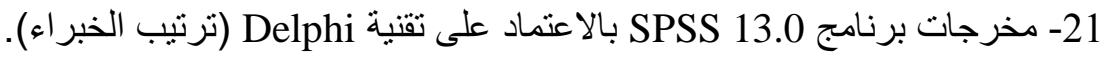

